\title{
Treatment and Outcome of Anterior Inferior Cerebellar Artery (AICA) Aneurysms: Helsinki Series of 15 Consecutive Patients.
}

Sajjad Muhammad ( $\sim$ Sajjad.Muhammad@med.uni-duesseldorf.de )

Heinrich Heine University Düsseldorf

Ahmad Hafez

Helsinki University Hospital

Hanna Kaukovalta

Helsinki University Hospital

Behnam Jahromi

Helsinki University Hospital

Riku Kivisaari

Helsinki University Hospital

Daniel Hänggi

Heinrich Heine University Düsseldorf

Mika Niemelä

Helsinki University Hospital

\section{Research Article}

Keywords: Anterior inferior cerebellar artery (AICA), intracerebral hemorrhage (ICH), subarachnoid hemorrhage (SAH), DSA

Posted Date: May 11th, 2021

DOI: https://doi.org/10.21203/rs.3.rs-477788/v1

License: (a) (1) This work is licensed under a Creative Commons Attribution 4.0 International License. Read Full License 


\section{Abstract}

Background: Anterior inferior cerebellar artery (AICA) aneurysms are rare posterior circulation lesions that are challenging to treat.

Objectives: To present the treatment and clinical outcome of AICA aneurysms in an unselected cohort of patients.

Methods: A retrospective analysis of patient record files, DSA and CT angiography images of 15 consecutive patients harboring AICA aneurysms treated between 1968 to 2017.

\section{Results:}

Eighty percent of the AICA aneurysm patients were females. Twenty percent presented with intracerebral hemorrhage $(\mathrm{ICH})$ and $40 \%$ had intraventricular hemorrhage. Eleven $(73 \%)$ patients suffered from subarachnoid hemorrhage (SAH); a good-grade SAH (Hunt and Hess grade 1-3) was observed in $82 \%$ SAH patients. Surgery was performed in $73 \%$ patients. Coil embolization was done in $7 \%$ patients and 20 $\%$ patients were treated conservatively. In $73 \%$ patients retrosigmoid approach was used and in $27 \%$ patients a sub-temporal approach with anterior petrosectomy was applied. A parent vessel occlusion was needed to occlude the aneurysm in $18 \%$ patients.

\section{Conclusion:}

Surgical treatment of AICA aneurysms has a high rate of cranial nerve deficits but most of patients have a good long-term clinical outcome. Surgical treatment may be an option only in selected cases of AICA aneurysms.

\section{Introduction}

Anterior inferior cerebellar artery (AICA) aneurysms are rare lesions and account for $<1 \%$ of all intracranial aneurysms ${ }^{1,2}$. Except a few larger case series ${ }^{3}$, only case reports with a single or a few patients have been reported ${ }^{1,4-63}$. Drake and colleagues reported a larger series of AICA aneurysms. However, they also included aneurysms originating from the basilar trunk near the origin of AICA. Both surgical and endovascular treatments of AICA aneurysms are challenging as these aneurysms are more often fusiform in morphology. Recent multicenter studies have shown that endovascular coiling has a better outcome than surgical clipping of posterior circulation aneurysms ${ }^{64}$. Although most of these trials included patients with posterior circulation aneurysms that harbored PICA or basilar bifurcation aneurysms, endovascular coiling has now been accepted as a favored treatment option for all posterior circulation aneurysms ${ }^{65}$. However, if parent vessel occlusion and a revascularization procedure is needed, surgery may still be a better choice in such selected cases due to the often larger size and fusiform shape of AICA aneurysms ${ }^{27,58}$. We report our series of patients harboring AICA aneurysms admitted during 1968 to 2017 to the department of Neurosurgery at Helsinki University Hospital. We 
discuss treatment options (including the role of surgery) for AICA aneurysms. Moreover, we discuss different surgical approaches for clipping AICA aneurysms, post-operative complications, and clinical outcomes in Helsinki series of AICA aneurysms.

\section{Methods}

\section{Patients and radiological data}

We retrospectively identified 21 patients with AICA aneurysms comprising $0.22 \%$ of the aneurysms admitted during the time period. After exclusion of aneurysms with missing CT angiography scans or DSA, 15 patients with AICA aneurysms were identified. Analysis of CT angiography images until 2007 was performed with a 4-slice scanner (GE Lightspeed QX/l; GE Medical Systems, Milwaukee, Wisconsin, USA) and later with a 32-slice scanner (GE LightSpeed Pro 32) or a 64-row scanner (GE lightSpeed VCT Advantage). Images were stored in the digital archiving system of the hospital (IMPAX, version 5.3, Agfa, Mortsel, Belgium). Analysis of CT angiography scans was performed by two board-certified neurosurgeons (figure 1).

The study was in accordance with the declaration of Helsinki. The patient data was completely anonymized. The study was approved by local ethical committee at Helsinki University. An additional approval for the collection of retrospective data or additional patient consent was not required.

\section{Clinical outcome}

For each patient we retrieved data on initial clinical grade on admission. Patients with Hunt and Hess grade 1 to 3 were classified as good clinical grade. Patients with subarachnoid hemorrhage (SAH) and patients with Hunt and Hess grade 4 to 5 were classified as poor grade SAH. Data on surgical approach and on postoperative cranial nerve deficits were retrieved from patient electronic record files. Clinical outcome was quantified using modified Rankin scale (mRS). Patients with mRS 1 to 2 were classified as good clinical outcome whereas patients with mRS 3 to 6 were classified as poor clinical outcome.

\section{Statistical Analysis}

Data were analyzed using the commercial statistical software IBM SPSS version 20.0.0. Data are presented in frequencies (percentage) or mean \pm SD.

\section{Results}

\section{Patients and presentation}

Of the 15 AICA aneurysm patients analyzed, 12 (80\%) were females and the remaining $3(20 \%)$ were males. Twenty percent had ICH and $40 \%$ presented with intraventricular hemorrhage (table 1). Eleven out of fifteen (73\%) patients presented with SAH and $82 \%$ of SAH patients had good-grade SAH (Hunt and Hess grade 1-3). 


\section{Treatment}

Four patients presented with cranial nerve deficits without SAH. Eleven patients (73\%) were treated surgically, 3 (20\%) were treated conservatively, and 1 (7\%) had coil embolization. In $27 \%$ of patients, a subtemporal approach with anterior petrosectomy was performed. In the remaining $73 \%$, the aneurysms were approached through a retrosigmoid approach with or without modifications. In $18 \%$ of the patients, a parent vessel occlusion was necessary to occlude the aneurysm.

\section{Clinical outcome}

Five out of eleven (47\%) of patients who underwent surgery developed post-operative cranial nerve deficits including oculomotor and abducens $(n=1)$, Abducens $(n=2)$, glossopharyngeus $(n=1)$ and Facial nerve palsy with hearing loss $(n=1)$. Twenty-seven percent developed shunt-dependent hydrocephalus. All patients who presented with an unruptured AICA aneurysm had good clinical outcome (mRS 1-2). In patients with SAH, $82 \%$ achieved good clinical outcome (mRS 1-2) and $18 \%$ had poor clinical outcome (mRS 3-6) after 1 year (table 2).

\section{Discussion}

Due to their often larger size and fusiform shape (in about $33 \%$ of cases), AICA aneurysms are a special group of posterior circulation aneurysms that may more often require surgery compared with other posterior circulation aneurysms. Selection of surgical approach is an important factor because of critical location of the aneurysm near important cranial nerves. There are two key factors that determine the approach during microsurgical clipping of AICA aneurysms. These are the height of the aneurysm in relation to the clivus and the segmental location of the aneurysm along the artery. High-lying AICA aneurysms can be accessed through a subtemporal approach with an additional petrosectomy. The farlateral approach is suitable for low-lying AICA aneurysms near the origin of the basilar artery. A retrosigmoid approach including its modifications is a simple and straightforward approach that can expose most parts of the AICA below the fifth cranial nerve and around the internal auditory meatus ${ }^{66}$. A lumbar drain is helpful to release CSF and increase the surgical exposure while operating through a retrosigmoid approach. In our series, 3 out of 11 patients were operated through a subtemporal approach with anterior petrosectomy and the other 8 were operated through a retrosigmoid approach with some extension according to location of the aneurysm. It is important to take special care to avoid injuring the sixth cranial nerve during anterior petrosectomy. In the series of Drake, most of the patients were treated through a subtemporal approach with a very high rate of post-operative sixth nerve injury. In our series, $46 \%$ (33\% already pre-operatively) of the patients presented cranial nerve deficits, which is lower than that reported in the literature ${ }^{3}$. The high rates of cranial nerve deficits are due not only to direct injury to the nerve but also vascular injury of the vasa nervorum, which can cause significant cranial nerve deficits ${ }^{40}$. Twenty-seven percent of patients developed shunt-dependent hydrocephalus, which is consistent with the literature. The overall clinical outcome in surgically treated patients is heavily dependent on the presentation status of the patient and the surgical skills of the neurosurgeon. In our series, all patients 
$(n=4)$ who presented with unruptured aneurysms achieved good clinical outcome (mRS 1-2). Patients who presented with good-grade SAH (Hunt and Hess grade 1-3; $n=9$ ) achieved good clinical outcome (mRS 1-2). Two patients with poor-grade SAH achieved poor clinical outcome (mRS 3-6). One patient in our series was coil embolized and had an initial Hunt and Hess grade 2; this patient also achieved mRS 2 at 1 year after treatment. For the conservatively treated patients, 1 patient who had SAH in 2003 lived until 2012 and reached mRS 3 at 1 year after SAH. One patient who was admitted with poor-grade SAH died after 1 day of hospitalization. The third patient in the conservative group who was admitted with SAH in 1968 achieved mRS 1 at 1 year after SAH. This patient later died due to prostate carcinoma. The reason for the low rate of rebleeding may be the high rate of thrombosis of these aneurysms. Although our surgical results are comparable to endovascular coiling, multicenter controlled and randomized trials in recent years have demonstrated that endovascular coiling is a better treatment for posterior circulation aneurysms. Thus, endovascular coiling has now become the standard first-choice treatment for all posterior circulation aneurysms (including AICA) in most neurosurgical centers worldwide.

\section{Limitations:}

Our analysis is retrospective and may not completely reflect the natural disease course. Due to the low number of patients, we could not analyze the influence of surgical approach and segmental location of the aneurysm on clinical outcome.

\section{Conclusion}

Although surgical treatment of AICA aneurysms has a high rate of cranial nerve deficits, most patients achieve a good long-term clinical outcome. Surgical treatment may still be an option in selected cases of AICA aneurysms. Based on this series and previous policy of our hospital to ignore endovascular therapy, it maybe not possible to give a clear recommendation. This is biased towards surgery.

\section{Declarations}

\section{Authors contribution}

Conceptualization: SM, MN, BRJ

Data Collection: SM, AH, HK, BRJ

Manuscript writing and statistical analysis: SM

Review of manuscript: SM, AH, HK, BRJ, RK, DH, MN

\section{Conflict of Interest}

Authors have no conflict of interest 


\section{Ethics approval}

The study was approved by local ethical committee at Helsinki University.

\section{Consent to participant}

An additional approval for the collection of retrospective data or additional patient consent was not required.

\section{Consent for publication}

The authors consent the publication of the article.

\section{References}

1. Li, X., Zhang, D. \& Zhao, J. Anterior inferior cerebellar artery aneurysms: six cases and a review of the literature. Neurosurgical review. 35, 111-119 discussion 119 https://doi.org/10.1007/s10143-0110338-1 (2012).

2. Sanai, N., Tarapore, P., Lee, A. C. \& Lawton, M. T. The current role of microsurgery for posterior circulation aneurysms: a selective approach in the endovascular era. Neurosurgery 62, 1236-1249; discussion 1249-1253, doi:10.1227/01.neu.0000333295.59738.de (2008).

3. Gonzalez, L. F., Alexander, M. J., McDougall, C. G. \& Spetzler, R. F. Anteroinferior cerebellar artery aneurysms: surgical approaches and outcomes-a review of 34 cases. Neurosurgery. $55,1025-1035$ (2004).

4. Adorno, J. O. \& de Andrade, G. C. [Aneurysm of the anterior inferior cerebellar artery: case report]. Arquivos de neuro-psiquiatria. 60, 1019-1024 (2002).

5. Aguiar, G. B. et al. [Fusiforme aneurysm of the anterior inferior cerebellar artery and arteriovenous malformation fed by the same vessel]. Medicina. 72, 245 (2012).

6. Akyuz, M. \& Tuncer, R. Multiple anterior inferior cerebellar artery aneurysms associated with an arteriovenous malformation: case report. Surgical neurology 64 Suppl 2, S106-108, doi:10.1016/j.surneu.2005.07.037 (2005).

7. Andrade, G. et al. Dissecting anterior inferior cerebellar artery aneurysm treated by endovascular route: report of three cases and review. Arquivos de neuro-psiquiatria. 68, 645-647 (2010).

8. Baskaya, M. K., Coscarella, E., Jea, A. \& Morcos, J. J. Aneurysm of the anterior inferior cerebellar artery-posterior inferior cerebellar artery variant: case report with anatomical description in the cadaver. Neurosurgery. 58, E388; discussion E388 https://doi.org/10.1227/01.neu.0000199344.63306.dd (2006).

9. Cantore, G. P., Ciappetta, P., Vagnozzi, R. \& Bozzao, L. Giant aneurysm of the anterior inferior cerebellar artery simulating a cerebellopontine angle tumor. Surgical neurology. 18, 76-78 (1982). 
10. DiMaio, S., Mohr, G., Dufour, J. J. \& Albrecht, S. Distal mycotic aneurysm of the AICA mimicking intracanalicular acoustic neuroma. The Canadian journal of neurological sciences. Le journal canadien des sciences neurologiques. 30, 388-392 (2003).

11. Ebara, M. et al. [A ruptured aneurysm of the anterior and posterior inferior cerebellar artery: a case report]. No shinkei geka. Neurological surgery. 27, 1013-1017 (1999).

12. Fukuya, T. et al. Aneurysms of the peripheral portion of the anterior inferior cerebellar artery; report of two cases. Neuroradiology. 29, 493-496 (1987).

13. Gleeson, M. J., Cox, T. C. \& Strong, A. J. Aneurysm of the anterior inferior cerebellar artery mimicking an intracanalicular acoustic neuroma. The Journal of laryngology and otology. 103, 107-110 (1989).

14. Gopalakrishnan, C. V., Menon, G. \& Nair, S. Aneurysm of the anterior inferior cerebellar artery-posterior inferior cerebellar artery variant: two case reports and review of literature. British journal of neurosurgery. 23, 554-556 https://doi.org/10.1080/02688690902987778 (2009).

15. Goto, S. et al. A case of ruptured intrameatal aneurysm successfully treated with coil embolization. Nagoya journal of medical science. 77, 307-313 (2015).

16. Honda, Y., Tanaka, R. \& Kameyama, S. Ruptured distal anterior inferior cerebellar artery aneurysmcase report. Neurologia medico-chirurgica. 34, 763-767 (1994).

17. Ishii, D., Takechi, A., Shinagawa, K. \& Sogabe, T. Endovascular treatment for ruptured distal anterior inferior cerebellar artery aneurysm -case report. Neurologia medico-chirurgica. 50, 396-399 (2010).

18. Ito, J. et al. [The anterior inferior cerebellar arteries originating from the internal carotid artery (author's transl)]. No to shinkei = Brain and nerve 31, $999-104(1979)$.

19. Jinbo, Y., Zheng, Z., Jiaquan, H., Hui, Y. \& Jun, L. Embolization of a ruptured aneurysm of the distal anterior inferior cerebellar artery with parent artery preservation. Neurol. India. 58, 786-788 https://doi.org/10.4103/0028-3886.72170 (2010).

20. Johnson, J. H. Jr. \& Kline, D. G. Anterior inferior cerebellar artery aneurysms. Case report. Journal of neurosurgery. 48, 455-460 https://doi.org/10.3171/jns.1978.48.3.0455 (1978).

21. Kanamori, F. et al. Ruptured partially thrombosed anterior inferior cerebellar artery aneurysms: two case reports and review of literature. Nagoya journal of medical science. 78, 517-522 https://doi.org/10.18999/nagjms.78.4.517 (2016).

22. Kang, H. S., Roh, H. G., Han, M. H. \& Koh, Y. C. Successful endovascular occlusion of a ruptured distal anterior inferior cerebellar artery aneurysm of the caudal trunk: case report. Interventional neuroradiology: journal of peritherapeutic neuroradiology, surgical procedures and related neurosciences. 13, 271-276 https://doi.org/10.1177/159101990701300306 (2007).

23. Kiya, K., Uozumi, T., Emoto, K. \& Matsuoka, T. Anterior inferior cerebellar artery aneurysm at the internal auditory meatus-case report. Neurologia medico-chirurgica. 29, 592-595 (1989).

24. Kiya, K., Uozumi, T., Emoto, K. \& Matsuoka, T. Aneurysm of the anterior inferior cerebellar artery at the internal auditory meatus: case report and review of the literature. Hiroshima journal of medical sciences. 38, 39-44 (1989). 
25. Koizumi, H. et al. Endosaccular embolization for a ruptured distal anterior inferior cerebellar artery aneurysm. Radiology case reports. 7, 651 https://doi.org/10.2484/rcr.v7i2.651 (2012).

26. Kyoshima, K., Matsuda, M. \& Handa, J. Cerebral aneurysm of the distal anterior inferior cerebellar artery: case report. Nihon geka hokan. Archiv fur japanische Chirurgie. 64, 139-145 (1995).

27. Lee, B. S., Witek, A. M., Moore, N. Z. \& Bain, M. D. Treatment of an Anterior Inferior Cerebellar Artery Aneurysm With Microsurgical Trapping and In Situ Posterior Inferior Cerebellar Artery to Anterior Inferior Cerebellar Artery Bypass: Case Report. Operative neurosurgery (Hagerstown, Md.). 15, 418$424 \mathrm{https} / / /$ doi.org/10.1093/ons/opx275 (2018).

28. Lee, S. J., Koh, J. S., Ryu, C. W. \& Lee, S. H. Ruptured intrameatal aneurysm of the anterior inferior cerebellar artery accompanying an arteriovenous malformation: a case report. Cerebellum (Lond., England). 11, 808-812 https://doi.org/10.1007/s12311-011-0349-z (2012).

29. Lv, X., Li, Y., Liu, A., Zhang, J. \& Wu, Z. Parent artery occlusion for peripheral anterior inferior cerebellar artery aneurysm. A case report and review of the literature. The neuroradiology journal. 21, 261-265 https://doi.org/10.1177/197140090802100219 (2008).

30. Mahmoud, M., El Serwi, A., Alaa Habib, M. \& Abou Gamrah, S. Endovascular treatment of AICA flow dependent aneurysms. A report of three cases and review of the literature. Interventional neuroradiology: journal of peritherapeutic neuroradiology, surgical procedures and related neurosciences. 18, 449-457 https://doi.org/10.1177/159101991201800411 (2012).

31. Marchini, A. K., Mosimann, P. J., Guichard, J. P., Boukobza, M. \& Houdart, E. Anterior inferior cerebellar artery aneurysms mimicking vestibular schwannomas. Journal of neuroimaging: official journal of the American Society of Neuroimaging. 24, 404-406 https://doi.org/10.1111/j.15526569.2012.00752.x (2014).

32. Martin, R. G., Grant, J. L., Peace, D., Theiss, C. \& Rhoton, A. L. Jr. Microsurgical relationships of the anterior inferior cerebellar artery and the facial-vestibulocochlear nerve complex. Neurosurgery. 6, 483-507 (1980).

33. Mascitelli, J. R. et al. Ruptured distal AICA pseudoaneurysm presenting years after vestibular schwannoma resection and radiation. Journal of neurointerventional surgery. 8, e19 https://doi.org/10.1136/neurintsurg-2015-011736.rep (2016).

34. Matsushige, T. et al. [Ruptured aneurysm arising from the anterior medullary segment of the posterior inferior cerebellar artery: report of two cases]. No shinkei geka. Neurological surgery. 32, 867-874 (2004).

35. Matsuyama, T., Okuchi, K., Norimoto, K. \& Ueyama, T. Ruptured dissecting anterior inferior cerebellar artery aneurysm-case report. Neurologia medico-chirurgica. 42, 214-216 (2002).

36. Menovsky, T., Andre Grotenhuis, J. \& Bartels, R. H. Aneurysm of the anterior inferior cerebellar artery (AICA) associated with high-flow lesion: report of two cases and review of literature. Journal of clinical neuroscience: official journal of the Neurosurgical Society of Australasia. 9, 207-211 https://doi.org/10.1054/jocn.2001.0945 (2002). 
37. Mizushima, H. et al. Aneurysm of the distal anterior inferior cerebellar artery at the medial branch: a case report and review of the literature. Surgical neurology. 52, 137-142 (1999).

38. Mori, K., Miyazaki, H. \& Ono, H. Aneurysm of the anterior inferior cerebellar artery at the internal auditory meatus. Surgical neurology. 10, 297-300 (1978).

39. Nakagawa, K., Sakaki, S., Kimura, H. \& Matsuoka, K. Aneurysm of the anterior inferior cerebellar artery at the internal auditory meatus. Surgical neurology. 21, 231-235 (1984).

40. Nishimoto, A. et al. Anterior inferior cerebellar artery aneurysm. Report of three cases. Journal of neurosurgery. 59, 697-702 https://doi.org/10.3171/jns.1983.59.4.0697 (1983).

41. Oh, J. S. \& Yoon, S. M. Endovascular treatment for ruptured distal anterior inferior cerebellar artery aneurysm. 16,20-25, doi:10.7461/jcen.2014.16.1.20 (2014).

42. Okumura, Y., Sakaki, T., Hirabayashi, H. \& Shimomura, T. Intrameatal aneurysm successfully treated by meatal loop trapping-case report. Neurologia medico-chirurgica. 39, 161-164 (1999).

43. Pasler, D., Baldauf, J., Runge, U. \& Schroeder, H. W. Intrameatal thrombosed anterior inferior cerebellar artery aneurysm mimicking a vestibular schwannoma. Journal of neurosurgery. 114, 1057-1060 https://doi.org/10.3171/2010.9.jns10491 (2011).

44. Pritz, M. B. Aneurysms of the anterior inferior cerebellar artery. Acta neurochirurgica. 120, 12-19 (1993).

45. Russegger, L. \& Furtschegger, A. [Aneurysms of the anterior inferior cerebellar artery. A case report and review of the literature]. Der Nervenarzt. 61, 499-503 (1990).

46. Saito, R., Tominaga, T., Ezura, M., Shimizu, H. \& Yoshimoto, T. [Distal anterior inferior cerebellar artery aneurysms: report of three cases and literature review]. No shinkei geka. Neurological surgery. 29, 709-714 (2001).

47. Santillan, A. et al. Endovascular management of distal anterior inferior cerebellar artery aneurysms: Report of two cases and review of the literature. Surgical neurology international. 2, 95 https://doi.org/10.4103/2152-7806.82577 (2011).

48. Santucci, N., Gazzeri, G. \& Magliocco, C. [Aneurysm of the anterior inferior cerebellar artery (AICA). 18th case in the literature]. Rivista di neurologia. 55, 30-37 (1985).

49. Skull base: official journal of North American Skull Base Society ... et al.] 14, 101-106; discussion 106-107, doi:10.1055/s-2004-828703 (2004).

50. Sasame, J. \& Nomura, M. Dissecting Aneurysm of Anterior Inferior Cerebellar Artery Initially Presenting with Nonhemorrhagic Symptom. Journal of stroke and cerebrovascular diseases: the official journal of National Stroke Association. 24, e197-199 https://doi.org/10.1016/j.jstrokecerebrovasdis.2015.03.055 (2015).

51. Singh, S., Mittal, R. S., Purohit, D. \& Shekhawat, J. Spontaneous resolution of ruptured dissecting anterior inferior cerebellar artery aneurysm: A rare case report. Asian journal of neurosurgery. 12 , 570-572 https://doi.org/10.4103/1793-5482.145561 (2017). 
52. Spallone, A., De Santis, S. \& Giuffre, R. Peripheral aneurysms of the anterior inferior cerebellar artery. Case report and review of literature. British journal of neurosurgery. 9, 537-541 (1995).

53. Suh, S. H. et al. Management of anterior inferior cerebellar artery aneurysms: endovascular treatment and clinical outcome. AJNR. American journal of neuroradiology. 32, 159-164 https://doi.org/10.3174/ajnr.A2360 (2011).

54. Sun, Y., Wrede, K. H., Chen, Z., Bao, Y. \& Ling, F. Ruptured intrameatal AICA aneurysms-a report of two cases and review of the literature. Acta neurochirurgica. 151, 1525-1530 https://doi.org/10.1007/s00701-009-0269-6 (2009).

55. Suzuki, K., Meguro, K., Wada, M., Fujita, K. \& Nose, T. Embolization of a ruptured aneurysm of the distal anterior inferior cerebellar artery: case report and review of the literature. Surgical neurology. 51, 509-512 (1999).

56. Takeuchi, S. et al. [Trapping of ruptured dissecting aneurysm of distal anterior inferior cerebellar artery-case report]. Brain and nerve = Shinkei kenkyu no shinpo. 61, 203-207 (2009).

57. Tamura, Y., Shirai, W. \& Tokumitsu, N. [Intrameatal Aneurysm of Distal Anterior Inferior Cerebellar Artery Manifesting a Subarachnoid Hemorrhage:A Report of 2 Cases]. No shinkei geka. Neurological surgery. 46, 673-681 https://doi.org/10.11477/mf.1436203792 (2018).

58. Taussky, P., Garber, S. \& Schmidt, R. H. Surgical management of a ruptured and unruptured distal anterior inferior cerebellar artery aneurysm. Report of 2 cases and review of the literature. Central European neurosurgery. 72, 108-111 https://doi.org/10.1055/s-0030-1268498 (2011).

59. Yamakawa, H., Hattori, T., Tanigawara, T., Sahashi, Y. \& Ohkuma, A. Intracanalicular aneurysm at the meatal loop of the distal anterior inferior cerebellar artery: a case report and review of the literature. Surgical neurology 61, 82-88; discussion 88(2004).

60. Yokoyama, S., Kadota, K., Asakura, T. \& Kawazoe, K. Aneurysm of the distal anterior inferior cerebellar artery-case report. Neurologia medico-chirurgica. 35, 587-590 (1995).

61. Zager, E. L. Isolated trigeminal sensory loss secondary to a distal anterior inferior cerebellar artery aneurysm: case report. Neurosurgery. 28, 288-291 (1991).

62. Zlotnik, E. I., Sklyut, J. A., Smejanovich, A. F. \& Stasenko, E. N. Saccular aneurysm of the anterior inferior cerebellar-internal auditory artery. Case report. Journal of neurosurgery. 57, 829-832 https://doi.org/10.3171/jns.1982.57.6.0829 (1982).

63. Zotta, D. C., Stati, G., De Paulis, D. \& Galzio, R. J. Intrameatal aneurysm of the anterior inferior cerebellar artery. Journal of clinical neuroscience: official journal of the Neurosurgical Society of Australasia. 18, 561-563 https://doi.org/10.1016/j.jocn.2010.06.019 (2011).

64. Molyneux, A. et al. International Subarachnoid Aneurysm Trial (ISAT) of neurosurgical clipping versus endovascular coiling in 2143 patients with ruptured intracranial aneurysms: a randomised trial. Lancet (London, England). 360, 1267-1274 (2002).

65. Spetzler, R. F. et al. The Barrow Ruptured Aneurysm Trial: 6-year results. Journal of neurosurgery. 123, 609-617 https://doi.org/10.3171/2014.9.jns141749 (2015). 
66. Bambakidis, N. C., Manjila, S., Dashti, S., Tarr, R. \& Megerian, C. A. Management of anterior inferior cerebellar artery aneurysms: an illustrative case and review of literature. Neurosurgical focus. 26, E6 https://doi.org/10.3171/2009.1.focus0915 (2009).

\section{Tables}

Table 1: Clinical presentation of anterior inferior cerebellar artery aneurysms $(n=15)$

\begin{tabular}{|lll|}
\hline & Mean & Percentage \\
\hline Presentation & & \\
\hline Males & 3 & 20 \\
\hline Females & 12 & 80 \\
\hline Intracerebral hemorrhage (ICH & & \\
\hline Intracerebral hemorrhage (ICH) & 3 & 20 \\
\hline No ICH & 12 & 80 \\
\hline Intraventricular hemorhage (ICV) & & \\
\hline Intraventricular hemorhage (ICV) & 6 & 40 \\
\hline No ICV & 9 & 60 \\
\hline Presntation (n=15) & & \\
\hline Unruptured & & 26.7 \\
\hline Ruptured & 4 & 63.3 \\
\hline Hunt and Hess grad (n=11) & & \\
\hline Hunt and Hess grad (1-3) & 9.2 \\
\hline Hunt and Hess grad (4-5) & 2 & \\
\hline
\end{tabular}

Table 2: Post-operative complications and clinical outcome of anterior inferior cerebellar artery aneurysms $(n=15)$ 


\begin{tabular}{|c|c|c|}
\hline & Mean & Percentage \\
\hline \multicolumn{3}{|l|}{ Presentation } \\
\hline \multicolumn{3}{|l|}{ Treatment } \\
\hline Conservative & 3 & 20 \\
\hline Coiling & 1 & 6.7 \\
\hline Clipping & 11 & 73.3 \\
\hline \multicolumn{3}{|l|}{ Approach $(n=11)$} \\
\hline Subtemporal + anterior petrosectomy & 3 & 27.3 \\
\hline Retrosigmoid (with its modifications) & 8 & 72.7 \\
\hline Parent vessel occlusion $(n=11)$ & 2 & 18.2 \\
\hline \multicolumn{3}{|l|}{ Post-OP Cranial nerve Deficits $(n=11)$} \\
\hline Yes & 5 & 46.5 \\
\hline No & 6 & 54.5 \\
\hline \multicolumn{3}{|l|}{ Hydrocephalus } \\
\hline Shunt dependent hydrocephalus & 4 & 26.7 \\
\hline No hydrocephalus & 11 & 73.3 \\
\hline Post-OP CSF leak & 1 & 9.1 \\
\hline \multicolumn{3}{|l|}{ Clinical outcome unruptured $(n=4)$} \\
\hline $\mathrm{mRS}(1-2)$ & 4 & 100 \\
\hline mRS (3-6) & 0 & 0 \\
\hline \multicolumn{3}{|l|}{ Clinical outcome ruptured $(n=11)$} \\
\hline mRS (1-2) & 9 & 81.8 \\
\hline mRS (3-6) & 2 & 18.2 \\
\hline
\end{tabular}




\section{Figures}

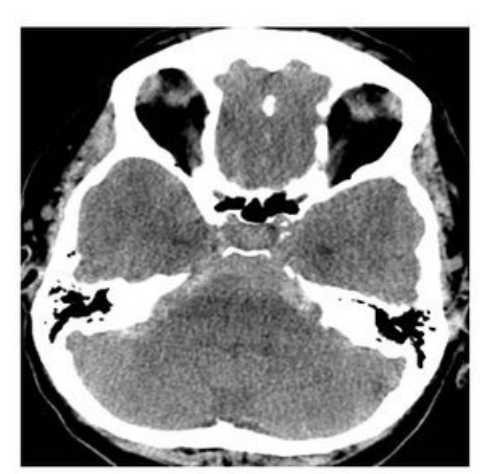

A

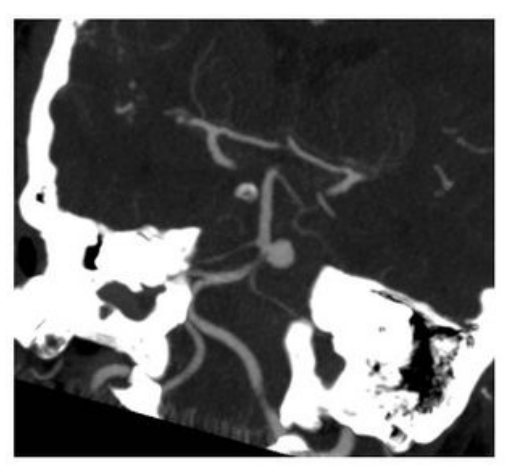

D

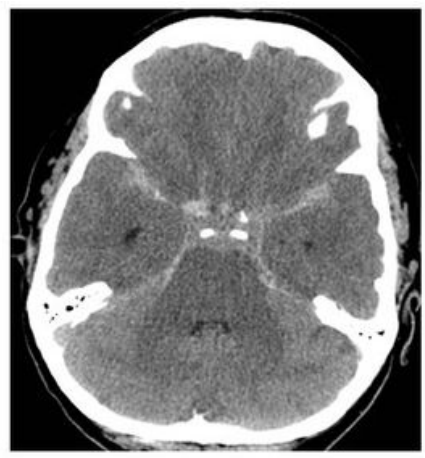

B

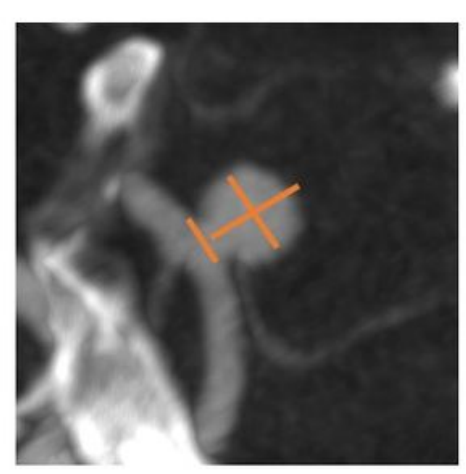

E

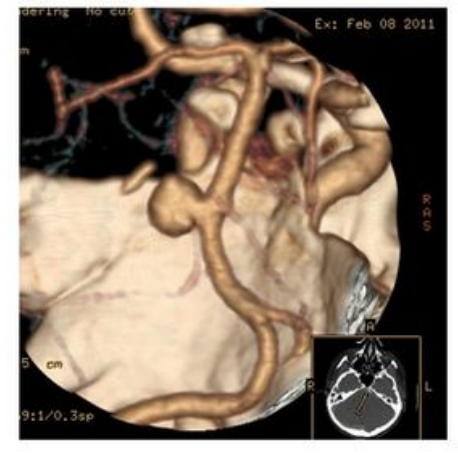

C

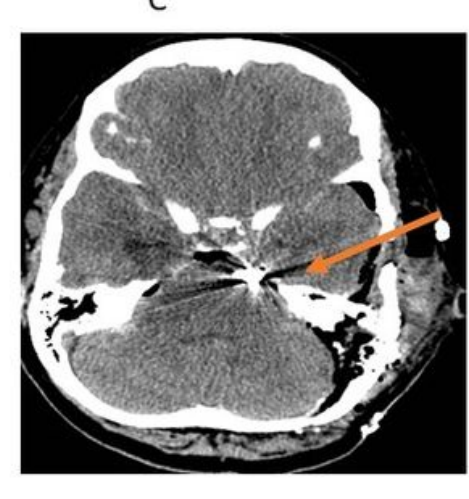

F

Figure 1

Computer tomography showing subarachnoid hemorrhage (A, B) from an AICA (proximal) aneurysm (C, $D, E)$. Aneurysm clipping was performed through a subtemporal approach (F). 